\title{
A Retrospective Study of the Yo-Yo IE2 Test: Can It be Used to Differentiate Between Different Levels of Futsal Referees?
}

\author{
D. Dixon* \\ Applied Sport and Exercise Sciences, School of Health Sport and Bioscience, University of East London. London, UK \\ *Corresponding author: d.dixon@uel.ac.uk
}

Received December 31, 2013; Revised January 14, 2014; Accepted January 17, 2014

\begin{abstract}
Recently FIFA have called on referees to be fitter and to look like athletes therefore the aim of this research was to retrospectively examine the results from the fitness test results undertaken by Futsal referees operating in and below the National Futsal League. Futsal is the FIFA sanctioned form of 5 a side football and is controlled by two referees who operate up and down the touchlines either side of the pitch. Research has shown that the referees operating at an average intensity of $76 \%$ heart rate maximum (HRmax)HRMAX and spent more time sprinting and working at high intensity compared to referees in the 11 a side game. Currently FIFA recommend a. and as such the current $1000 \mathrm{~m}$ run, but this is not thought to match the actual movements or intensity of futsal referees or matches. As such the Yo-Yo IE2 test was introduced this season as it has been found to correlate highly with high intensity running $(r=0.75 ; \mathrm{p}<0.05)$. Twenty-two National group and 36 Non-national group futsal referees underwent pre-season testing which in-cooperating the Yo-Yo Intermittent Endurance Level 2 Fitness Test, a $40 \mathrm{~m}$ sprint test and a $70 \mathrm{~m}$ agility run test. The result showed a trivial effect size difference for Yo-Yo IE2 test distance (0.21), a small effect size difference for $40 \mathrm{~m}$ speed test and a extremely large effect size difference for $70 \mathrm{~m}$ agility run. A moderate to large correlation was found between age and Yo-Yo IE2 distance $(\mathrm{r}=-0.577)$ and BMI and YoYo IE2 distance $(\mathrm{r}=-0.452)$. Therefore the Yo-Yo IE2 can be used to differentiate between different levels of futsal referees and it may be possible to use the test to identify those referees who show the fitness attributes for further development.
\end{abstract}

\section{Keywords: fitness testing, Yo-Yo IE2, futsal, referee, indoor soccer, physiology}

Cite This Article: D. Dixon, "A Retrospective Study of the Yo-Yo IE2 Test: Can It be Used to Differentiate Between Different Levels of Futsal Referees?" American Journal of Sports Science and Medicine, vol. 2, no. 3 (2014): 93-97. doi: 10.12691/ajssm-2-3-5.

\section{Introduction}

Futsal is the only 5 -a-side form of football that is officially sanctioned by FIFA. The main differences between this type of football and its 11 a side version are that it is played indoors on a pitch that measures $40 \times 20$ metre and is played over a time of $20 \mathrm{~min}$ each way. However, in Futsal the clock is stopped every time the ball goes out of play so in reality each half usually lasts between 30 and $40 \mathrm{~min}$. The game itself is classed as an intermittent high-intensity sport with players changing directions / activity about every 3.28 seconds [1] which is helped by the players being able to undergo unlimited substitutions without stopping play [2].

The Referee is responsible for enforcing the laws of the game in invasion type sports such as Futsal. However, unlike the 11 a side version, it is refereed by two referees who operate up and down the touch lines. Although there is an increasing amount of research examining the physiological and psychological demands of the 11 a side referee and assistant referees, which have shown that
Assistant referees, undergo intense brief bouts of forward and sideways running [3]. However, there have been very few papers which examine the physiological demands of futsal referees. Research by [4] examined the physiological demands of Futsal referees using the Portuguese first division referees. It was found that the average heart rate of the futsal referees during matches was 146 beats.min-1 which equated to $76 \%$ of their HRmax. Research by [4] showed that Futsal referees undergo different movement patterns compared to their 11 a-side counterparts and for the majority of the game, futsal referees spend more time completing high intensity (HI) and maximal sprints, although these bouts of $\mathrm{HI}$ and maximal sprints are for a shorter periods of time.

\subsection{Referee Futsal Fitness Test}

Currently the futsal referees have a battery of test which include an endurance run (1000 $\mathrm{m}$ in $4 \mathrm{~min})$, a sprint test (2x 40 metre sprint in less than 10 seconds) and an agility test (to be completed in less than 20 seconds and consisting of running, sprinting, sideways running and backwards running over a 30 metre course) [5]. All of 
these are usually conducted on a track in the weather conditions of the particular fitness test date, which in the English climate can be very variable and not conducive to the climate in which they would normally operate. Therefore it would be more appropriate if a test could be conducted indoors, the match environment, and in particular could differentiate between the different levels of referees.

\subsection{Yo-Yo IE2 Fitness Test}

The Yo-Yo IE2 fitness test is a test which can be used indoors over a 20 metre track. Research by [6] reports that the Yo - Yo test is highly correlated with high intensity running (HIR) $\quad(\mathrm{r}=0.75 ; \mathrm{p}<0.05)$. To the authors knowledge there has been only one study which has examined the use of the Yo Yo IE 2 test in which the data was compared to futsal referees [4]. In that paper the referees underwent the Yo Yo IE 2 where an average distance of $975 \mathrm{~m}$ was covered by the referees. A correlation was conducted between HIR and IE2 distance $(\mathrm{r}=0.52 \mathrm{p}<0.05)$. A smaller significant correlation was found with total match distance covered $\mathrm{r}=0.40 \mathrm{p}<0.05$ and no correlation with match intensity ( $\%$ of HR) $r=0.02$ $\mathrm{p}>0.05$ [5] which according to [7] these would be classed as having a large correlation magnitude for HIR and IE2, a moderate magnitude for the match distance and IE2 and a trivial magnitude for IE2 and match intensity.

The test used needs to fit in with the ethos of FIFA to get the best referees, refereeing the best games, this test would seem to be able to differentiate between the referees from both groups as there was a significant difference in the total distance run between the two groups. This would be important for the development of referees on the national list and to allow the management of the game to know who would be in line for nomination to FIFA especially as this International organisation can work outside the European laws on age discrimination. As such they only allow referees to be nominated who are between 23 and 35 years [8].

Therefore the selected test needs to relate to the ability of the referee to officiate in matches which involve a large amount of time at high intensity running. It is also important that the test has some relationship with the actual movements in a futsal match and that the test being administered has been shown to deliver repeatable and consistent results.

\section{Material and Methods}

Fifty Eight referees (56 male and 2 female) undertook the Yo-Yo IE-2. However, the test was conducted on two different days to reflect the two different groups undertaking the test.

The first group was made up of thirty six referees (34 male and 2 female) undertaking the test in order to seek promotion into the National Group. These referees were made up of those who act as third official on the National League and either referee National League Division 2 or University Futsal matches.

The second test day was made up of twenty two referees (22 male) who were all referees within the current National group who referee on the National and Super Futsal League.
The Anthropometric data for the two groups reproduced in Table 1.

Prior to both tests an informed consent form, BASES health questionnaire and PARQ were completed by each referee, all referee who answered 'Yes' to any of the questions had to bring the information to my attention. Following the completion of the form, the referees were required to complete three tests, the Yo-Yo IE2 test, a 40 metre sprint test and a sixty metre agility test.

\subsection{Yo-Yo Test IE2}

This test consists of two cones placed $20 \mathrm{~m}$ apart with a further third cone positioned $2.5 \mathrm{~m}$ behind the start cone. The object of the test is to run between the two 20 metre cones reaching each end exactly at the time signal given by the test CD. After each $40 \mathrm{~m}$ the referee has a 5 second break in which to run slowly around the third cone and back to the start ready for the next signal. If the referee is too quick, they must wait at the marker until the next signal. If the referee is too slow a warning is given and on the second time the test is stopped [9].

On both occasions the referees were allowed to warm up for $10 \mathrm{~min}$ prior to the start of the Yo-Yo IE2 test.

During the second bank of testing test heart rate was recorded continuously for eight of the twenty-two referees taking part. The heart rates were sampled every 5 seconds using Polar Team2 (version 1.4.5, Polar Electro Oy, Finland) from about $20 \mathrm{~min}$ before the test started until the completion of all the tests.

Two other tests were also conducted on each day, a forty metre sprint test where the participant is required to run $40 \mathrm{~m}$ between two lines $10 \mathrm{~m}$ apart and a seventy metre agility test where the participant is required to $70 \mathrm{~m}$ running forwards, sideways and backwards [5]. Speed Light Timing gates placed 1 metre above ground were used to record the individual referee sprint and agility times (Brower Timing Systems, Utah, USA).

The data is presented as means and standard deviation. The correlations were established using the Pearsons product moment test and the magnitude were considered in accordance with Hopkins definitions [7].

\section{Results}

Anthropometric and fitness data are presented in Table 1. With regard to the referees' anthropometric data, the national group of referees were older and heavier than the non-national group of referees. For fitness test performance, national group of referees covered more distance on the Yo - Yo IE 2 test and recorded faster $40 \mathrm{~m}$ and $70 \mathrm{~m}$ sprint times.

Table 1. Anthropometric charteristic and test results of the groups $($ mean \pm SD)

\begin{tabular}{|c|c|c|c|}
\hline & $\begin{array}{c}\text { Nation Group } \\
\text { Mean } \pm \text { SD }\end{array}$ & $\begin{array}{c}\text { Non-nation } \\
\text { Group } \\
\text { Mean } \pm \text { SD }\end{array}$ & $\begin{array}{c}\text { Effect size for the } \\
\text { different }( \pm 90 \% \\
\text { confidence interval) }\end{array}$ \\
\hline Age $(\mathrm{Yrs})$ & $36.9 \pm 9.9$ & $32.0 \pm 11.5$ & $0.35(-0.10 \text { to } 0.79)^{* *}$ \\
\hline Weight $(\mathrm{Kg})$ & $81.3 \pm 10.3$ & $79.8 \pm 10.4$ & $0.17(-0.28 \text { to } 0.61)^{*}$ \\
\hline Height $(\mathrm{m})$ & $178.3 \pm 9.0$ & $177.0 \pm 8.1$ & $0.19(-0.25 \text { to } 0.63)^{*}$ \\
\hline BMI $\left(\mathrm{Kg} / \mathrm{m}^{2}\right)$ & $25.6 \pm 2.3$ & $25.5 \pm 3.3$ & $0.00(-0.44$ to 0.44$)$ \\
\hline YoYo $(\mathrm{m})$ & $1002 \pm 325.1$ & $927 \pm 304$ & $0.21(-0.24 \text { to } 0.65)^{*}$ \\
\hline $40 \mathrm{~m}$ test $(\mathrm{s})$ & $9.9 \pm 0.5$ & $10.2 \pm 0.6$ & $-0.48(-0.92 \text { to }-0.03)^{* *}$ \\
\hline $70 \mathrm{~m}$ test $(\mathrm{s})$ & $18.7 \pm 0.8$ & $19.41 \pm 1.9$ & $10.51(8.71 \text { to } 12.02)^{* * *}$ \\
\hline
\end{tabular}


The data in Figure 1 below is from the eight referees who wore the monitors and it would appear that all eight referees were close to their maximal values (172-204 beats.min-1) at the point of volition and as such the test has tested them fully and is a valid test for the referees. The average for the eight referees over the whole test was 164.76 beats.min-1 $(s=16.49)$ which equates to about $89 \%$ of heart rate maximum (HRmax) based on the average age of the eight referees was 35 years (range $17-$ 49 years), although the HRmax range was $88-104 \%$.

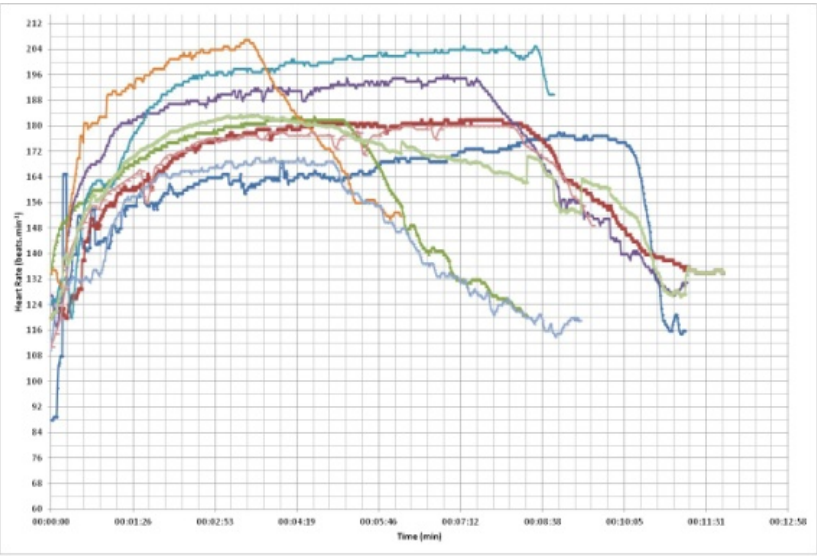

Figure 1. Heart Rate Data for National Group YO-YO IE2 Test

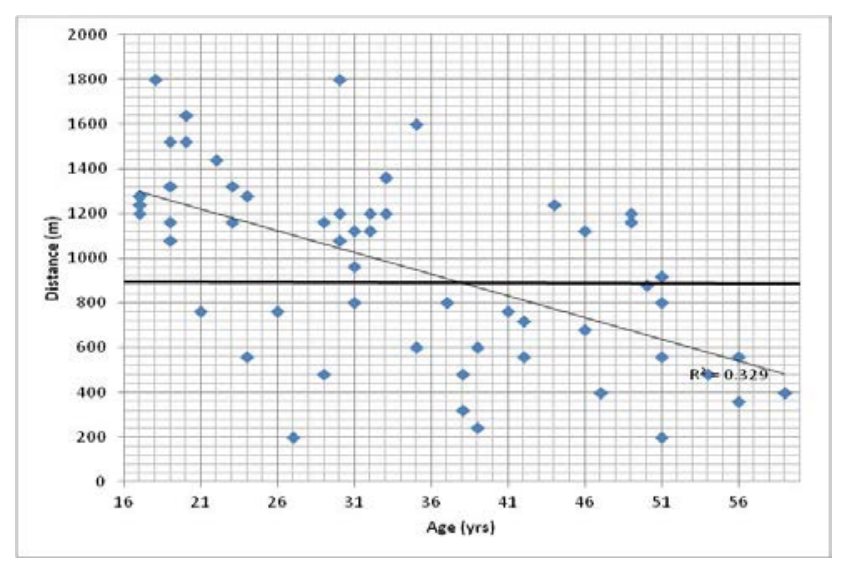

Figure 2. Comparison of referees Age vs. Distance travelled during YO - YO IE2 Test for both National and Non National Groups

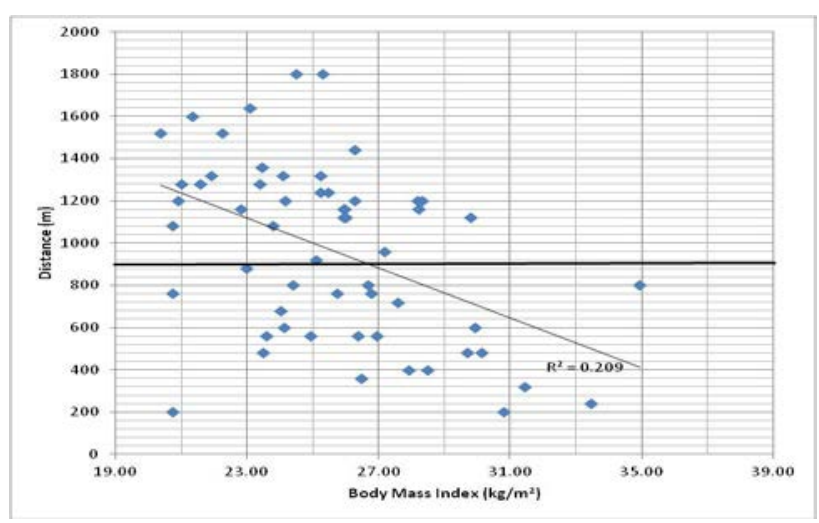

Figure 3. Comparison of referees BMI vs. Distance travelled during YO - YO IE2 Test for both National and Non National Groups

Analysis on the combined data of the two groups to see if there was a relationship between any of the variables and the distance covered in the Yo-Yo test. Moderatelarge correlations were observed between referee age and
Yo - Yo IE 2 distance $(\mathrm{r}=-0.577 ; 90 \%$ confidence interval -0.71 to -0.41 ) (Figure 2) and referee BMI and Yo - Yo IE 2 distance ( $r=-0.452 ;-0.61$ to -0.2$)$ (Figure 3$)$.

\section{Discussion}

This initial study showed that the Yo-Yo IE2 can be used to differentiate between age and BMI. It can also be used as a form of talent identification for those referees who may be fit enough to work as potential FIFA referees and that the heart rates

In relation to talent identification of future FIFA referees, the Yo - Yo IE 2 test showed that there was a trivial for Yo - Yo IE2 distance (1002 vs. 927), a small effect for the 40 metre sprint test ( 9.9 vs. 10.2 seconds) and an extremely large effect for the 70 metre agility test ( 18.7 vs 19.4 seconds). As such the test would seem to be suitable to differentiate between the different levels of the referees with the national group running further and being faster in the 40 metre speed and 70 metre agility tests. Although in relation to the 40 metre and 70 metre tests the time taken to do each test was below that set by FIFA for their international referees (40 metre being 10 seconds and 70 metre being 20.5 seconds) [5] which then asks the question whether the time set for these tests sufficiently reflects the amount of training required and the speed of the game at the elite level. As such more research should be completed in this area.

Unlike other research in this area, there is no positional or intra and inter seasonal data. However, at the recent gathering of referees by FIFA an emphasis was placed on the fact that referees needed to become athletes and that fitness and body composition is becoming an important factor in their selection process $[8,12]$. The data from these tests indicates that there was a moderate to large correlation between the distance covered in the $\mathrm{Yo}_{\mathrm{O}}-\mathrm{Yo}_{\mathrm{o}}$ IE2 test and the age of the participants and their BMI. As such the Yo - Yo IE2 could be used to identify the referees who may meet these new areas set by FIFA and UEFA $[8,10]$. However, BMI is not the best test of body composition in relation to physically active participants, and in such circumstance \% body fat should be used. However, it was not possible to test everyone during this testing period, although a similar moderate correlation was found between $\%$ body fat and the distance completed in the Yo-Yo IE2 $(\mathrm{r}=-0.378 ; 90 \%$ confidence interval -0.65 to -0.02) [11] when a twenty two of the fifty eight referees were tested. As such further investigation could be made into whether percentage body fat is a sole factor or part of a number of factors which dictate the distance covered in the Yo-Yo IE2.

The heart rates sampled during the test show that the referee's heart rate increased as the test became harder and in such cases the heart rate is said to reflect the amount of oxygen taken up by the body [12] and at exhaustion the heart rate was on average $89 \%$ of HRmax. This is below those reported in other research [13], but the age range of the referee group is considerable wider than that found in player research. Although it may have been better if Blood Lactate samples had been taken to confirm that the aerobic system was sufficiently taxed and as such the anaerobic system has been stimulated [9]. 
The distance covered by the national group in the YoYo IE2 test were slightly higher than the mean result found in the 18 elite Portuguese Futsal referees $1002 \mathrm{~m}$ versus $975 \mathrm{~m}$, [4], but the non-national group mean was less than the elite referee group (927 vs. $975 \mathrm{~m}$ ), although both groups were considerable less than the average distance said to be covered by elite soccer players $(2600 \mathrm{~m})$ [9]. However, the Yo - Yo IE 2 test has been shown to have a moderate to large correlation with the match distance covered both by elite soccer players $(\mathrm{r} 2=0.55)$ [13] and elite referees $(\mathrm{r} 2=0.4)$ [4]. As can be seen that there is a larger correlation with the players this may be due to the referees being reactive to the tactics employed by the players. However, as there has been only one study involving futsal referees in a professional league, more research should be conducted in a non-professional environment.

In the research by [4] a moderate to high correction was found between match distance and high Intensity running. However, there was no report as to whether there was any correction between the distance covered in the Yo-Yo IE 2 test and the distance covered moving side wards. This would be an important factor as this was the second highest movement pattern of the referee $(911 \mathrm{~m})$ [4] and is reports as $1610 \mathrm{~m}$ of the $5780 \mathrm{~m}$ in another study of Portuguese referees [14], the latter being similar to that covered by FIFA Assistant referees [15]. However, in [14] there was no correlation found in the distance covered in the Yo-Yo SFIE2 (also called ARIET) and side wards movement, although this test may have more validity as it includes an element of side wards running as part of the test. Although it would appear that referees with poor physical fitness test results preforming the most side wards running [14]. However, as this is not an official futsal fitness test there is as the author understands it no minimum standard for the referees to pass which may be a factor in the results.

\section{Conclusions}

The results of this study have established that the YoYo IE2 can be used to differentiate between different levels of futsal referees who operate in the National Futsal Division One and Two. The test can also be used to possible identify those referees who show the fitness attributes for further development based on the criteria of age and body composition as suggest by FIFA. Unfortunately it was not possible to capture any actual match activity profiles during this stage of testing and as such further research is needed to explore whether there is a correlation between the high intensity movements, side wards running and /or match distance covered by futsal referees in national league games and the distance covered in the Yo - Yo IE2 test compared to professional leagues [4].

More recently the Yo-Yo SFIE2 which is the same type of test as the Yo-Yo test with the addition of a side wards movement leg in between each run may be more akin to the movement of futsal referees. This new test has also shown a large correlation with match values [14] from professional futsal leagues. Therefore further research needs be conducted into the validity of the Yo-Yo IE2/ Yo-Yo SFIE2 and match values for match distance, HIR and sprinting by referees operating in non-professional futsal leagues.

\section{Acknowledgement}

This study did not receive any funding. However we would like to thank the English Football Association and the effort from all the English Futsal referees involved in this study, without whose participation, this study would not have been possible.

\section{Statement of Competing Interests}

None.

\section{List of Abbreviations}

$\begin{array}{llll}\text { ARIET } & \begin{array}{l}\text { Assistant Referee } \\ \text { Endurance Test }\end{array} & \text { Intermittent } \\ \text { BASES } & \begin{array}{l}\text { British Association of } \\ \text { Exercise Scientists }\end{array} & \text { Sport and } \\ & \begin{array}{l}\text { Body Mass Index } \\ \text { BMI }\end{array} & & \\ \text { FIFA: } & \begin{array}{l}\text { Fédération Internationale de } \\ \text { Association }\end{array} & \text { Football } \\ \text { HRmax } & \text { Heart Rate Maximum } & \\ \text { HI } & \text { High Intensity } & \\ \text { m } & \text { metres } & \\ \text { PARQ } & \text { Physical Activity } & \text { Readiness } \\ \text { SFIE2 } & \text { Questionnaire } & \\ & \text { Sidewards-Forwards } & \text { Intermittent } \\ \text { UEFA } & \text { Endurance Level 2 } & \\ & \text { Union of European } & \text { Football } \\ & \text { Associations } & \end{array}$

\section{References}

[1] Dǒgramaci, SN, Watsford, ML, A comparison of two different methods for time-motion analysis in team sports. International Journal of Performance and Analysis in Sport, 6(1), pp73-83, 2006

[2] Barbero, JC, Soto VM, Granda J, Match analysis and heart rate of futsal players during competition. Journal of Sports Sciences, 27, (1), pp1-11, 2007.

[3] Krustrup, P, Mohr, M, and Bangsbo, J, Activity profile and physiological demands of top-class soccer assistant refereeing in relation to training status. Journal of Sports Sciences, 20, pp 861871, 2002.

[4] Rebelo, AN., Ascensão, AA., Magalhães, J. F., Bischoff, R., Bendiksen, M., \& Krustrup, P. Elite futsal refereeing; activity profile and physiological demands, The Journal of Strength and Conditioning Research, 25(4), pp 980-987, 2011.

[5] FIFA Regulations on the Organisation of Refereeing in FIFA Member Associations.

http://www.fifa.com/mm/document/tournament/competition/01/28 /10/42/defs_regulationsorganisationrefereeinginfifama_inhalt.pdf. Downloaded on 15th November 2013.

[6] Weston, M., Castagna, C., Impellizzeri, F.M., Bizzini, M., Williams, A.M., and Gregson, W. Science and medicine applied to soccer refereeing: an update. Sports Medicine 42, pp 615-31, 2012

[7] Batterham, AM. and Hopkins, WG. 'Making meaningful inferences about magnitudes', International Journal of Sports Physiology and Performance, 1 (1), pp.50-57, 2006.

[8] UEFA Futsal referees given fitness guidance http://www.uefa.org/footballfirst/matchorganisation/refereeing/ne ws/newsid=2024421.html, downloaded 13th November 2013.

[9] Bangsbo, J. \& Mohr, M. Fitness Testing in Football: fitness training in Soccer II. Bangsosport, 2011. 
[10] UEFA. Referees urged to set standards http://www.uefa.org/footballfirst/matchorganisation/refereeing/ne ws/newsid=1990079.html. Downloaded 3rd September 2013.

[11] Dixon D. (2013). Unpublished data from fitness testing of FA Futsal referees.

[12] Saltin B. Physiological effects of physical conditioning. Medicine and Science in Sport. 1(1). pp50-56, 1969.

[13] Bradley, P. S., Mohr, M., Bendiksen, M., Randers, M. B., Flindt, M., Barnes, C., Hood, P., Gomez, A., Andersen, JL., Di Mascio, M., Bangsbo, J. and \& Krustrup, P. Sub-maximal and maximal Yo-Yo intermittent endurance test level 2: heart rate response, reproducibility and application to elite soccer. European journal of applied physiology, 111(6), pp969-978, 2011

[14] Krustrup P., Randers, MB., Horton, J., Brito, J. and Rebelo, A Ecological validity of the Yo-Yo SFIE2 test. International Journal of Sports Medicine, 33; pp432-438, 2012.

[15] Castagna, C., Bendiksen, M., Impellizzeri, F. M. \& Krustrup, P. Reliability, sensitivity and validity of the assistant referee intermittent endurance test (ARIET) - a modified Yo-Yo IE2 test for elite soccer assistant referees, Journal of Sports Sciences, 30(8), pp767-775, 2012. 